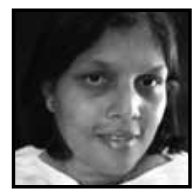

\title{
Portraying Children's Voices Through Creative Approaches to Enhance Their Transition Experience and Improve the Transition Practice
}

Divya Jindal-Snape, University of Dundee

\section{ABSTRACT}

In this paper, I have made a case for using creative approaches to facilitate educational transitions. I have presented examples from research and practice which suggest that creative activities can be used in multiple ways to portray children and young people's voices. I argue that these voices, as well as the process of being heard, can help modify existing transition practices, identify new transition practices, and enhance children and young people's ability to manage change. Theories of self-esteem, resilience, and emotional intelligence have been used to explain the psycho-social processes that a child, or young person, goes through during transitions, as well as how creative approaches can be used to support these processes.

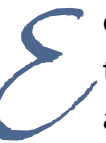

ducational transitions, when children move from one context and set of interpersonal relationships to another (Jindal-Snape, 2010a), can be a period of anxiety for many children and young people' (Adeyemo, 2007; Jindal-Snape \& Foggie, 2008; Jindal-Snape \& Miller, 2008), and can lead to substantial declines in self-esteem, academic motivation, and achievement (Wigfield, Eccles, Mac Iver, Redman, \& Midgley, 1991). However, transitions can be, and should be, a time of excitement due to increased opportunities and feelings of progression. Important changes take place as children navigate this journey, such as changes in relationships, teaching style, environment, space, context for learning, and so on (Fabian \& Dunlop, 2005). 
According to recent research (Jindal-Snape, 2010a), for children and young people to have positive transition experiences, there should be an increased emphasis on involving those most affected, especially the children themselves, in planning and preparation for transitions. Galton (2010a) has stressed the importance of schools listening to the voices of pupils. Researchers in the area of primary-secondary and post-school transitions have tried to listen to the voices of children and young people (e.g., Jindal-Snape \& Foggie, 2008), whereas few researchers in the area of transition to primary school (e.g., Dockett \& Perry, 2004) have managed to portray the voices of very young children. In addition, even when data has been collected from children and young people it is not clear whether the children/young people found data collection techniques such as questionnaires or interviews meaningful. There are serious methodological and ethical issues in this context, with only a few researchers using other ways that might be more meaningful to the child or young person and adopting a stance that children should be active and effective partners in research (e.g., Dockett \& Perry, 2011). Future transition research and practice needs to focus on listening to the voices of children in ways that are natural and meaningful to them. Researchers and practitioners really need to engage with children to gather their perspectives, not only to understand their unique experiences, but also to ensure that they are active participants in determining transition practice and programs. Innovative and creative ways of listening to children should be considered, for example, the Mosaic Approach (Clark \& Moss, 2001, 2008), which uses different ways of collecting voices such as giving children disposable cameras and through observation (JindalSnape, 2010b), and then piecing together the data to get a fuller and clearer picture.

The rationale for the use of creative approaches provided in this paper is also supported by other research. In the context of 19 creative learning case studies from Scottish schools, Learning and Teaching Scotland (LTS) (2004) reported that one of the main outcomes for students was a sense of personal success. Similarly, in the United States, Schacter, Thum, and Zifkin (2006) reported that creative teaching methods substantially improved student achievement. Research conducted in the United Kingdom also indicated that these approaches could lead to increased levels of pupil motivation and engagement (Bancroft, Fawcett, \& Hay, 2008; Craft, Chappell, \& Twining, 2008; Cremin, Burnard, \& Craft, 2006; LTS, 2004; Wood \& Ashfield, 2008), increased levels of confidence and imagination associated with creative environments (Galton, 2010b; LTS, 2004), enhanced ability to face challenges (Galton, 2010b) and increases in resilience (Bancroft et al., 2008).

Further, other researchers have also suggested that creative approaches can enhance children and young people's emotional development and social skills 
(Bancroft et al., 2008; Galton, 2010b; Matthews, 2007; Whitebread, Coltman, Jameson, \& Lander, 2009). Whitebread et al. (2009) suggest that play promotes self-regulation, and Bancroft et al. (2008) suggest that it can enhance interpersonal skills, including greater willingness to play with others, value each other's work, and engage in negotiation.

However, how does one go about using creative approaches to facilitate transition by building in strategies to enhance children's self-esteem, resilience, emotional intelligence, and agency? This paper draws on some examples of creative approaches and activities that are grounded in the theories of self-esteem, resilience, emotional intelligence, and agency. The examples presented here demonstrate how we can listen to the voices of children with the aims of facilitating their transitions and improving existing transition practices.

\section{Examples of Creative Activities Used in Transition Research and Practice}

This paper discusses some of the creative activities that I have used for transition research and that practitioners have used in practice. The aim is to give both researchers and practitioners a clear rationale of why these are appropriate and important ways of facilitating transition, and an idea of how to implement these in your own research and practice. The examples aim to provide you with insight into how, if carefully implemented, self-esteem, resilience, active learning agency, and emotional intelligence interact in the context of transitions leading to positive spirals of successful adaptation.

Let us consider some of these theories before we move on to the examples. In the context of transitions, Jindal-Snape and Miller $(2008,2010)$ used Mruk's two-dimensional theory of self-esteem which looks at the students' experiences and interactions in the light of self-competence and self-worth (Mruk, 1999). This two-dimensional theory reflects the belief that how people feel about themselves is dependent, not only on whether they see themselves as worthwhile people, but also involves judgments about competence in a set of domains considered important to them. Therefore, to have high self-esteem, children must feel confident both about their sense of self-worth ("I am a good person entitled to respect from others") and their sense of self-competence ("I am able to meet the challenges I face in life") (Jindal-Snape \& Miller, 2010, p. 13). During transition, the sense of self-worth 
and/or self-competence can be easily challenged, based on changing relationships with peers and teachers as well as the perceived ability to undertake higher level academic tasks. Therefore, it is important that children are able to go through transitions without their self-esteem being adversely affected. Self-esteem can be an important factor in developing resilience to challenges during transition. Resilience has been defined as a dynamic process of adaptation and the ability to thrive when faced with adverse situations. Resilience research (Luthar, 2006) suggests that whether an individual is resilient or not, is dependent on internal attributes (e.g., self-esteem) and the protective factors in their environment (e.g., positive relations with teachers or peers). Therefore, resilience becomes important, during both transition research and practice, as it provides us with insight into how we can ensure that children are resilient during this period of significant change; which for some might create adverse situations (Jindal-Snape \& Miller, 2008).

Similarly, Adeyemo $(2007,2010)$ has focused on emotional intelligence interventions and suggests that children and young people need psychological skills and resources that can help them with adaptations, adjustments, and an understanding of self that is required to navigate this journey. He suggests that this is because they need skills to relate with peers and teachers, and also to understand their own emotions and use that understanding to relate to others. The ability to regulate one's own emotions and, in turn, to be able to manage those of others requires a degree of self-regulation and agency. This agency can be developed better when children experience autonomy and feel in control. Other researchers have also discussed the importance of the "active learning agency" (i.e., "a capacity for intentional and responsible management of new learning," Pietarinen, Soini, \& Pyhältö, 2010, p. 144), "active participation," and/or "feeling in control" in successfully navigating the transition process (Akos, 2010; Galton, 2010a; Jindal-Snape, 2010b). This can lead to increases in motivation to learn, resilience and self-esteem, especially the two-dimensional selfesteem seen in terms of self-competence and self-worth (Jindal-Snape \& Miller, 2010).

\section{Photographs}

Photographs can be a powerful medium for listening to children's voices as well as helping them prepare for transition. Photovoice has been used as a participatory action research method that enables "participants to use their photographs to elicit emotions, feelings, and insights about topics that may have been shrouded in silence" (Lopez, Eng, Robinson, \& Wang, 2005, p. 326). It has been used to provide opportunities for participants to speak from their own experiences, to see connections between them, and to share these experiences in order to discover the root 
cause of some problem (Freire, 1970, cited in Cooper \& Yarbrough, 2010). As such, photographs can be used to discuss issues that might be of importance to children when making the move to another school or school year. The child can take control of the situation by deciding on what photographs to take and being able to express his or her views fully.

Gorton (2012) gave children in a nursery setting a digital camera and asked them to take photos of their own setting. She then asked each child to sort these using "happy," "sad," and "ok" faces and downloaded the photographs onto a laptop computer. The children were given a card with each face (happy, sad and ok) on to indicate their choice. They also had the option to point to an icon of the same face on the computer. She repeated this process with the children when they were in primary school, and asked them to take photos of their new setting and then to sort them as mentioned earlier. These photos and allocated faces were used to discuss children's feelings about leaving nursery, what they were excited about, what had worked well for them, and more importantly why. This seemed an effective way of collecting the views of 4 to 6 year olds who had autism as this gave them an alternative way of communication. Their views, along with the views of their parents and professionals who had worked with them, provided insights into how transition practices could be improved, as well as this triangulation of perspectives providing methodical rigour to the data collected through photos and highlighting when the views of adults and children did not match.

In the context of primary-secondary transitions, photographs taken by others have also been used to probe children's views about transition and transition practices by showing them photographs of abstract objects and asking them to use the images to project their excitement or concerns regarding transition, and evaluate the system in place (Jindal-Snape, Baird, \& Miller, 2011; see Board Game later for an example). On the basis of previous feedback from parents about problems experienced by their children due to lack of familiarity with the physical environment and significant people in a primary school, for the next cohort, the head teacher provided photographs of significant others and important places that the child and parents could look at before starting school. In an online questionnaire, administered six months after their children had started primary school, parents highlighted the photographs as one of the most beneficial aspects of the transition preparation undertaken by the school (Jindal-Snape, 2009).

... useful having photos which we showed to our son every now and then to remind him that school was approaching, "this is your teacher, this is your classroom" etc etc. A very useful tool for getting them into that way of thinking. (p. 8) 
According to Davies (2011), using cameras can help children see familiar objects in an unfamiliar way and also to observe them from a different perspective. As mentioned earlier, in Jindal-Snape (2009), nursery school children used the photographs taken by others to look at unfamiliar objects and people to familiarize themselves and develop a bond prior to starting school. Therefore, photographs became an important way of capturing views as well as an important familiarization tool, thus providing crucial opportunities to children to understand their own emotions and prepare them better for the new environment leading to enhanced resilience.

\section{Sketches}

Children's drawings can be very powerful in conveying messages that they might be consciously and subconsciously giving to others. Sketches were used to find out children's views of transition (Jindal-Snape \& Foggie, 2009; Jindal-Snape et al., 2010). They were asked to draw freely to indicate their expectations, concerns, experiences, etc. These were then used to generate a dialogue with them. Figure 1 shows an example of how a child felt after the induction day at a secondary school (JindalSnape, Miller, \& Baird, 2010).

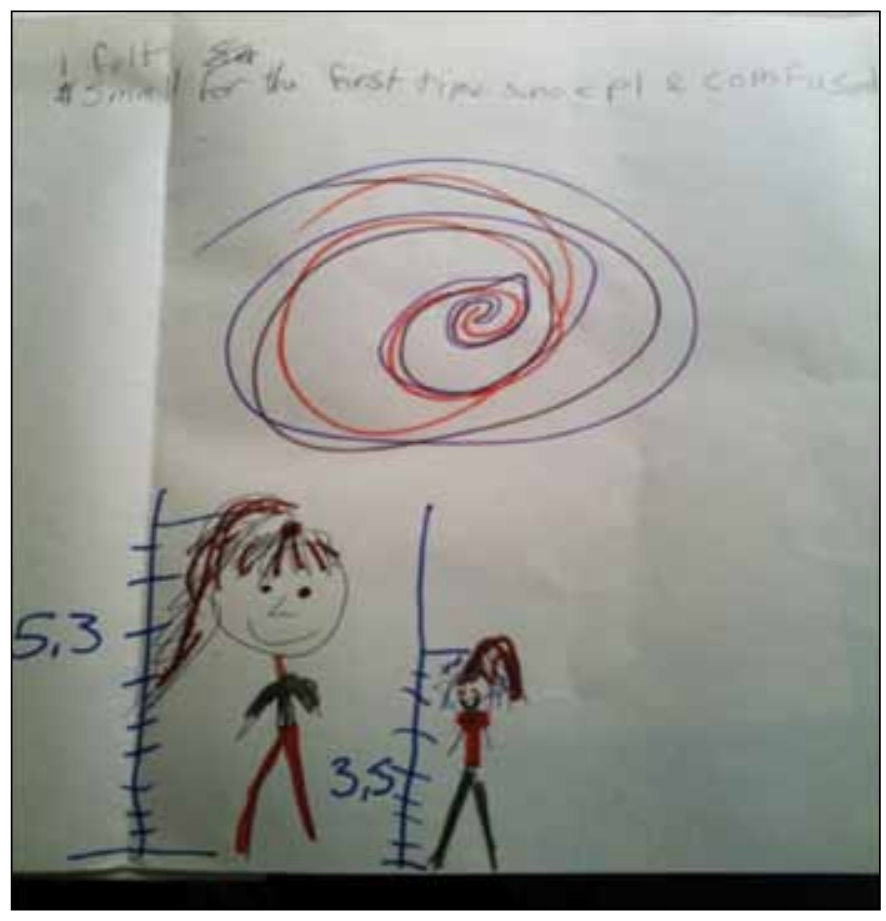

Fig. 1: Sketch to express views regarding the move to secondary school 
As you can see, she also added that, "I felt small for the first time since P1 (first year of primary school) \& comfused (confused)." However, the symbolic nature of the change in height represented by the scales on the left and the two images of the girl show her feelings even more clearly.

Similarly, in another study, after failing to get much dialogue going with young people about life transitions following participation in an alternative curriculum project, their sketches gave a good forum to start the discussion (Jindal-Snape \& Foggie, 2009). Figure 2 provides an example of such a sketch.
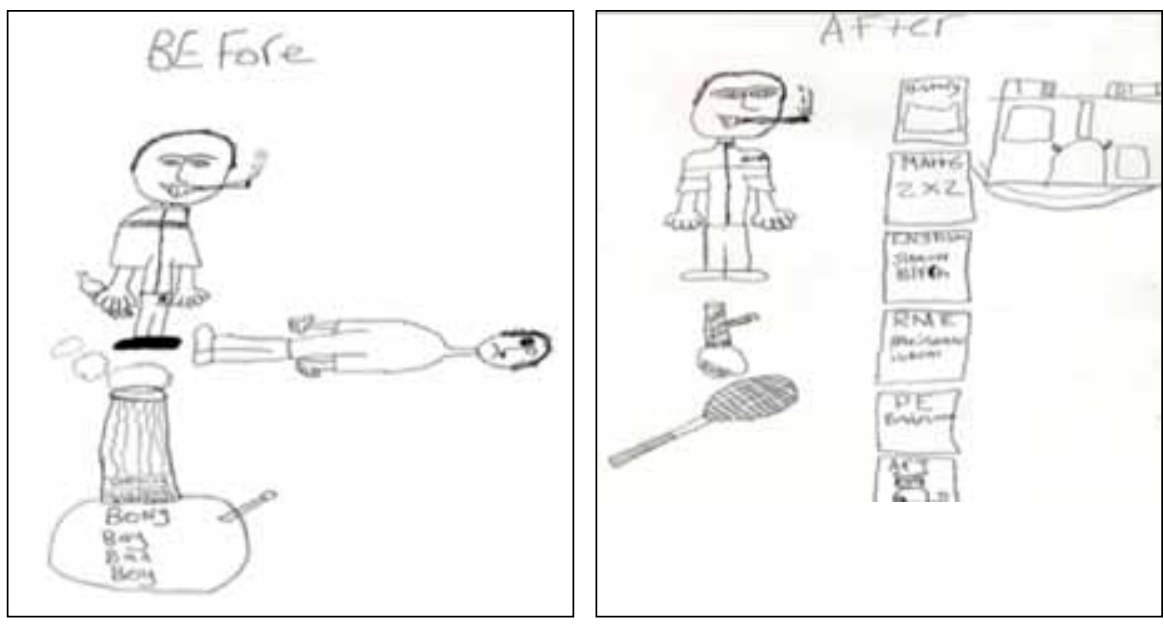

Fig. 2: Example of young person's voice regarding effectiveness of an alternative curriculum project

As you can see, in the two sketches the young person was able to portray different aspects of his life (Figure 2). This sketch is powerful as it visually conveys how much the use of drugs had reduced, and how instead of lying around the house, the young person started taking different lessons and playing tennis. It portrays aspects that probably words alone could not. Most importantly, it acted as a springboard for discussion. In this type of creative approach, however, it is important that we do not end up becoming gatekeepers (Csikszentmihalyi, 2002, cited in Davies, 2011) and make value judgments of their sketches or perceived to be doing so by children and young people. There should be a shared understanding that the sketch is important to convey their experience and not for its aesthetic value. Again, this opportunity to express themselves fully gives children a sense of agency as the discussion is controlled by them on the basis of their sketch. Further, both sketches provided opportunities to express their emotions, thus facilitating a good understanding of their self 
which would help regulate these emotions in the future, leading to better emotional intelligence and resilience.

\section{Board Games}

As mentioned earlier, when working with children, it is important to consider ways of collecting their voices in a way that is more natural or meaningful to them. Playing comes naturally to children and its role in early years is well documented (Davies, Jindal-Snape, Collier, Digby, Hay, \& Howe, 2012). However, there is also evidence that games-based approaches can support creativity at all ages (Cremin et al., 2006; Cumming, 2007; European Commission 2009; Miller, Hudson, Miller, \& Shimi, 2010). According to Davies (2011) a skilled practitioner can involve children in "sustained shared thinking" (p. 36) by engaging effectively in children's play.

A board game ${ }^{2}$ was used to collect views of 11-12-year-olds about their experience of primary to secondary transition (Jindal-Snape, Baird et al., 2011). This board game was designed based on research conducted by Jindal-Snape in the area of primary-secondary transition in Scotland between 2006 and 2010 as well as on research carried out by others (e.g., Galton, 2010a). The areas included in the text on the board game were highlighted as aspects that facilitated successful transition if implemented well, and areas of concern or excitement for children (Jindal-Snape, forthcoming). Data, on which the text in the game were based, were collected by Jindal-Snape from young people, their parents, and professionals regarding experience of transition along with an in-depth review of literature in this area. The board game was piloted with three children in the age group of 10-12 years and refined on the basis of their feedback.

After the focus group was over, the children were asked about their views on using a board game to facilitate it. Feedback was very positive; children said that they found it easier to respond to questions as part of the game rather than responding to questions posed by an adult researcher.

I thought it was good. I thought it was better because the last time someone came they were just asking questions. So I liked this better because you get to have fun as well.

It was interactive.

It was a good way to get us talking. 
Although this board game was specifically created for this purpose, it is possible to adapt commercially available board games.

The same board game can be used with children to help facilitate transitions. The teacher or parent can use the scenarios in the boxes as cues for discussion about school. The scenarios can be used by teachers to provide information to the children; or by parents to make a note of questions to ask the child's primary/secondary school teacher/s. This game can be used in small groups with children in class. The object of the game ${ }^{3}$ is not to win but to have a good discussion about these areas and make a note of any areas that should be discussed with the primary or secondary school teachers/parents/child in future.

Similar board games can be used with children about to start primary school. Some student teachers have used the board game and provided positive feedback about it.

My students (student teachers) have used your board game with their pupils when on placement in schools. They have provided very positive feedback on how the game was effectively used with children.

(Personal communication, Gwen Boswell, 7.12.2011)

According to Gandini, Hill, Cadwell, and Schwall (2005), on the basis of observations in Reggio Emilia schools in Italy, regularly practiced dialogue can support and sustain a culture and community that thinks together, with interpersonal exchange, negotiation of conflict, and comparison of ideas and actions supporting this process. This board game can provide children, parents, and teachers with an aid for creating such dialogue, clearly linking with emotional intelligence and opportunities to practise resolution of any conflicts. This can also enhance the resilience of the child by effective support provided in these dialogues by family, teachers, and peers.

\section{Storybooks}

Parents in Jindal-Snape (2010c), and Hannah, Gorton, and Jindal-Snape (2010) suggested that children should be given a chance to practise activities and rules that are new to them in a simulated setting. This is similar to the drama approach discussed later. With this in mind the author created storybooks for children focusing on different issues such as making friends, uniforms, bilingualism, and so on. 
For example, one story book is based on research with children moving to primary school (Jindal-Snape, Snape, \& Snape, 2011) that suggests that children's worries revolve around making friends, knowing the difference in rules of the primary school compared to the preschool setting, adults expecting them to be independent, and dealing with different behaviours according to the context they find themselves in (Jindal-Snape, 2010b). The objectives of this storybook are to explore children's worries about starting school, rehearse in a safe environment the possible actions in response to others' behaviour, discuss possible consequences of their actions, and to explore positive ways of making friends.

The story can be used with an individual child, or a group of children, to discuss the different responses that the child/ren might have to a scenario. The facilitator involves them in the story by asking what they might do in a similar situation, and provides opportunities of talking through their reaction to the situation and potential consequences. The basic story starts with a scenario, such as this one, where some children are playing and one child comes and pushes another child. ${ }^{4}$

The children are then asked to discuss what might happen next. They can talk about reactions of other children; reflect on the consequences of those actions, feelings of each child in the scenario, and reasons behind those feelings. These are good opportunities for enhancing the child's emotional intelligence. Some options of what might happen are given in the story, but the idea is to let the children take ownership of the story and develop it in whatever direction they want to, with the purpose of enhancing their active learning agency. The examples of consequences in the story can also be used to discuss the change in rules, children's concerns, positive ways of making friends, and so forth. It is worth noting that the second and third authors of the book are 10 and 8 year-old children who designed the options, consequences, and dialogues. This was done to ensure that the story was meaningful and natural to young children and portrayed their voices rather than that of the adult (Jindal-Snape, Snape et al., 2011).

The storybook was piloted with children, parents, and professionals and refined on that basis. The feedback so far has been positive. However, data has not been gathered to see its impact on transition experiences and is an area worth exploring in future. Again, storybooks with age appropriate characters in a relevant context can give children opportunities to personalize (I would...) or depersonalize (She should...) and practise what they would do in a similar scenario (Boal, 1995). Storybooks like these can be used by practitioners and parents; ideally this idea can be used to create their own stories. 


\section{Creative Drama}

As mentioned earlier, it has been suggested that prior to transition, children/ young people should be involved in simulated role-play, drama, and story-telling to provide opportunities to express their transition concerns and tackle them in a secure and familiar environment, thus making them more resilient. Creative drama can again be used as a means of constructing a plausible real-life scenario in which the actors can depersonalize their actions and responses in the guise of "playing the character" (Jindal-Snape, Vettraino et al., 2011, p. 2). Creative drama is important for children engaging in the experience of moving schools as it helps them understand the process of change and ways of managing that process. Similar to Boal's (1995) metaxis, "the state of belonging completely and simultaneously to two different, autonomous worlds; the image of reality and the reality of the image" (p. 43), children can participate in drama and observe how they, or others, might behave in drama and reality. If this creative drama is based on their context, it can provide them with opportunities to learn and rehearse real-life situations in a safe environment. The environment is safe as it is part of their natural environment with familiar peers and teachers, and they have the additional protection of playing out "somebody else's life" rather than their own. They can play out important scenarios, their reactions and consequences to their reactions within the protected guise of "drama" - a fictional piece of work. This can then free them up to openly reflect and debate, gain a greater understanding to help interpret potential real life situations, make appropriate behaviour choices to engage with those situations, and learn from the successful outcomes of those situations (Jindal-Snape, Vettraino et al., 2011). Other research has also suggested that such creative activities can enhance a child's confidence and self-esteem (JindalSnape \& Foggie, 2008) and promote resilience (Akos, 2004; Newman \& Blackburn, 2002). You can use different scenarios such as first day at school, bullying, making friends, peer pressure, and so on for creative drama. Ideally these should come from the children themselves through other drama games, sketches, stories, and so forth that the teacher might already be using in class.

Drama professionals have also been positive about the use of drama for transitions (Jindal-Snape, Vettraino et al., 2011):

... I think it's the power of drama that we do create a level playing field ... and also begin to discover voices we never knew existed, the children never knew they had...

As soon as you ask children about what's going on in their head they won't tell it. But when you create a character... then it becomes a lot easier... (then) there is 
no sense of exposure or vulnerability there... we've created a believable enough character where children from P7 (final year of primary school in Scotland) to S1 (first year of secondary school in Scotland) face similar sort of problems - suddenly they are freed up... (pp. 7-8)

Therefore, when discussing "level playing field," "no exposure or vulnerability," they are suggesting clear links with resilience and self-esteem. An example of creative drama activity is available in Jindal-Snape, forthcoming.

\section{Discussion and Conclusion}

The examples from practice and research evidence suggest that children's self-esteem, emotional intelligence, agency, and resilience can be enhanced through involvement in creative approaches such as drama, story-telling, and games-based learning. In this way, children and young people are provided with secure exposure to transition related issues and given opportunities to tackle them. Overall, it can be seen that whether we listen and portray voices in the context of research or practice, creative approaches can help improve transition practice for individual children and others. As mentioned earlier, research suggests that creativity frees children and gives them a voice to articulate their views (Bancroft et al., 2008). Above all, a combination of different creative approaches (as well as in conjunction with more traditional approaches) gives each child the opportunity to choose what he or she might be most comfortable with and interested in. Although these creative techniques have some similarities with the ideas behind the Mosaic Approach, they are different in that they have been structured based on transitions research with a strong grounding in theory. Also, they are based on over 30 years of international research on school transitions.

These approaches provide children with opportunities to control their environment and the context of learning. They are creating their own world-whether real or fictitious. The elements of creativity not only engage and motivate them, but also the process, and indeed the output, can lead to increases in self-esteem. Further, as was mentioned by professionals in Jindal-Snape, Baird et al. (2011) and JindalSnape, Vettraino et al. (2011), creative approaches provide a level playing field for every child. They suggest that this is because the focus is not on academic skills, but is about "active learning" and imagination. 
Being able to practise real-life scenarios in a safe environment with peers and adults they are familiar with, can prepare them for such situations in a new environment. Being able to understand the consequences of potential actions helps them manage risks in their new environment. They are able to rehearse key life skills in the "make believe" world of drama or storybooks. They develop emotionally and socially, and become more resilient. As Newman and Blackburn (2002) have said, it is important not to avoid risk, but to successfully manage it. These creative approaches give opportunities to do just that. If we see transition as an ongoing process (Jindal-Snape, 2010a), we need to keep using these approaches even after the move has been made. On the basis of this, I propose a model that establishes the links between creative approaches, voices, and subsequent improvement in transition experience (Figure 3). This model suggests that voices heard through creative, and child- and youngpeople-appropriate techniques, can have multi-fold benefits. It can help practitioners revise existing transition practices as well as identify new techniques that can be used (In Figure 3, starting in a bottom-up manner, these are the two boxes on the left and middle of level 3). For instance, Galton (2010a) gives an example of how a group of children suggested that instead of schools just giving a map of the secondary school for a tour of the school (commonly existing transition practice), schools could set up a treasure hunt which could involve working in teams using that map to find their way around the new school (a suggestion for new transition practice). Further, creative approaches can be used for the child to learn to manage changes and work through any issues. Carrying on with the above-mentioned example, the treasure hunt will provide a child with the opportunity for problem solving in a safe environment with peer support, where concerns of "being lost" will be overridden by the game of treasure hunt (In Figure 3, starting in a bottom-up manner, this is the box on the right of level 3). All these lead to a child feeling more in control and having a more positive sense of self-worth and self-competence reinforced by adults' willingness to listen and modify their practice. All these then help the child have more positive transition experiences and also act as a buffer against any negative experiences thanks to increased self-esteem and resilience. 


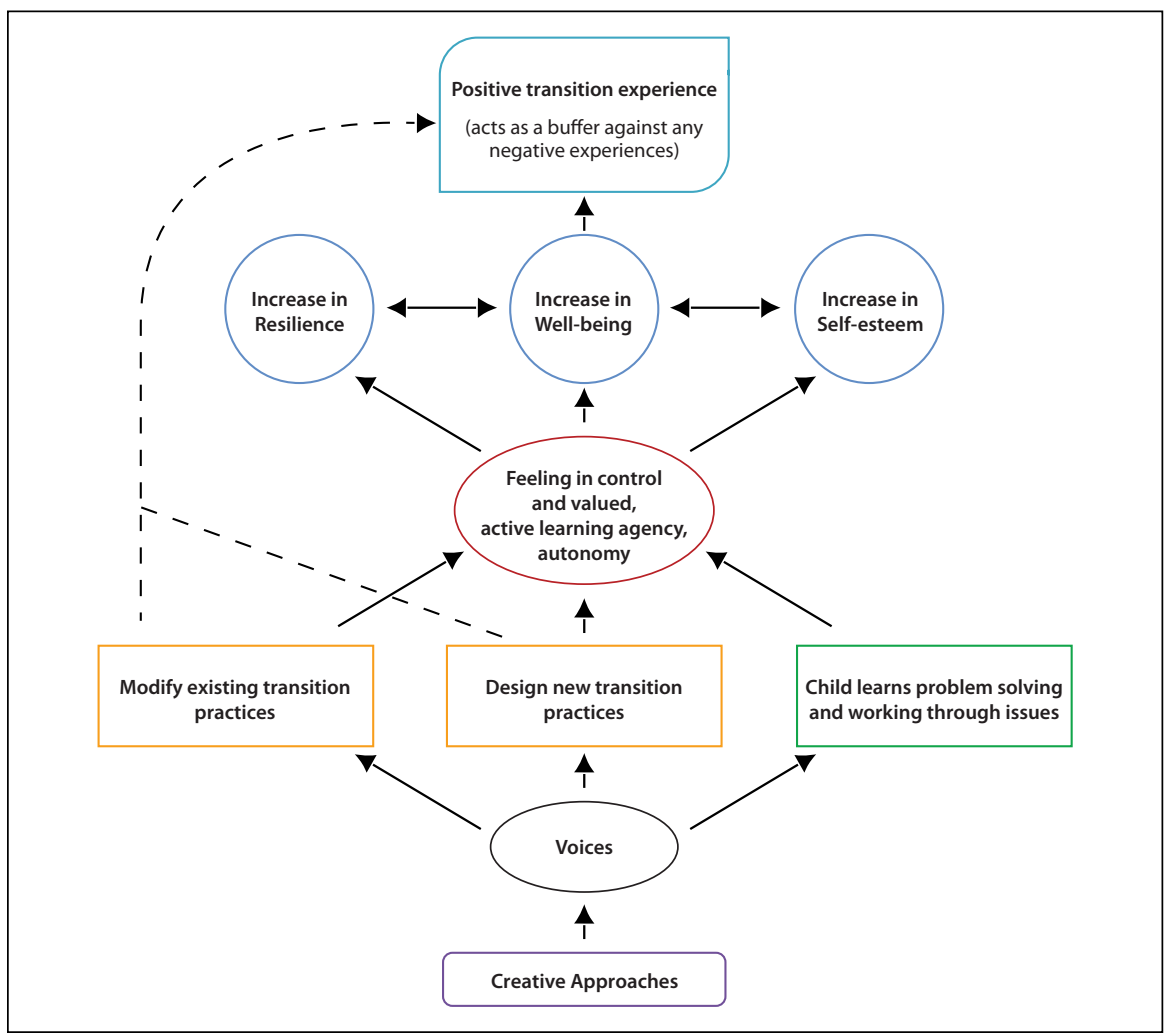

Fig. 3: Using creative approaches to portray voices to facilitate transitions through enhancement of resilience, well-being, and self-esteem

\section{Potential Issues and Considerations}

It is also important to understand that not all adults are comfortable using creative approaches. In a study done by Jindal-Snape, Baird et al. (2011), some teachers did raise concerns about knowing less than the children when using computer games during the transition process. Other research into creativity has also suggested that some teachers are not comfortable and they need training in facilitating creativity (Jindal-Snape, Vettraino et al., 2011). This also places an increased responsibility on teacher trainers to use similar creative approaches with student teachers to provide them opportunities to take such risks and develop the confidence to "let go of control" and allow for more autonomy. Davies et al. (2012) suggest that it is important to provide continuing professional development (CPD) for teachers that helps them discuss their preconceptions of creativity, gives opportunities to have dialogues around models of creativity and pedagogy, and provides opportunities to develop their own creativity. 
Researchers have also pointed out barriers to using creative approaches in schools, namely, statutory requirements, organizational barriers, and pedagogical barriers to taking risks (Davies et al., 2012; Wyse \& Spendlove, 2007). However, given that there is increasing evidence of the benefits of using creative approaches, the educational policy and practice has to change. To create a school ethos which is conducive to creativity, supportive leadership is very important (Grainger, Goouch, \& Lambirth, 2005). In the context of Scotland, with the emphasis on Curriculum for Excellence (LTS, n.d.) and assessment for learning, this might become easier. In other countries where similar curricular reforms have taken place such as New Zealand, Italy, Sweden and Finland, again there is more scope for the use of creative approaches, and indeed there are some very good examples of how they are used (e.g., Peters, 2010).

\section{Notes}

1. In this paper, "children" refers to individuals up to 11 years of age and "young people" denotes individuals aged 12 to 16 .

2-4. Please see http://www.dundee.ac.uk/eswce/people/djindalsnape/transitions/for further information.

\section{References}

Adeyemo, D.A. (2007). Moderating influence of emotional intelligence on the link between academic self-efficacy and achievement of university students. Psychology and Developing Society, 19(2), 199-213.

Adeyemo, D.A. (2010). Educational transition and emotional intelligence. In D. JindalSnape (Ed.), Educational transitions: Moving stories from around the world ( $\mathrm{pp}$. 33-47). New York: Routledge.

Akos, P. (2004). Advice and student agency in the transition to middle school. Research in Middle Level Education, 27, 1-11.
Akos, P. (2010). Moving through elementary, middle, and high schools: The primary to secondary shifts in the United States. In D. Jindal-Snape (Ed.), Educational transitions: Moving stories from around the world (pp. 125-142). New York: Routledge.

Bancroft, S., Fawcett, M., \& Hay, P. (2008). Researching children researching the world: $5 \times 5 \times 5=$ creativity. Stoke-on-Trent, UK: Trentham.

Boal, A. (1995). The rainbow of desire: The Boal method of theatre and therapy. London: Routledge. 
Clark, A., \& Moss, P. (2001). Listening to young children: The mosaic approach. London, UK: National Children's Bureau Enterprises Ltd.

Clark, A., \& Moss, P. (2008). Spaces to play: More listening to young children using the mosaic approach. London, UK: National Children's Bureau Enterprises Ltd.

Cooper, C.M., \& Yarbrough, S.P. (2010). Tell meshow me: Using combined focus group and photovoice methods to gain understanding of health issues in rural Guatemala. Qualitative Health Research, 20(5), 644-653.

Craft, A., Chappell, K., \& Twining, P. (2008). Learners reconceptualising education: widening participation through creative engagement? Innovations in Education and Teaching International, 45(3), 235-245.

Cremin, T., Burnard, P., \& Craft, A. (2006). Pedagogy and possibility thinking in the early years. Thinking Skills \& Creativity, 1(2), 108-119.

Cumming, R. (2007). Language play in the classroom: encouraging children's intuitive creativity with words through poetry. Literacy, 41(2), 93-101.

Davies, D. (2011). Teaching science creatively. London: Routledge.

Davies, D., Jindal-Snape, D., Collier, C., Digby, R., Hay, P., \& Howe, A. (2012). Creative learning environments in educationA systematic literature review. Thinking Skills and Creativity. Retrieved from http:// dx.doi.org/10.1016/j.tsc.2012.07.004

Dockett, S., \& Perry, B. (2004). Starting school: Perspectives of Australian children, parents and educators. Journal of Early Childhood Research, 2(2), 171-189.

Dockett, S., \& Perry, B. (2011). Naked by the pool? Blurring the image? Ethical issues in the portrayal of young children in arts-based educational research qualitative inquiry. Journal of Early Childhood Research, 17, 3-14.

European Commission.(2009). Creativity in Schools in Europe: A Survey of Teachers. Retrieved from http://create2009.europa.eu
Fabian, H., \& Dunlop, A. (2005). The importance of play in the transition to school. In J.R. Moyles (Ed.). The excellence of play, 2nd edition. Berkshire: Open University.

Galton, M. (2010a). Moving to secondary school: What do pupils in England say about the experience? In D. Jindal-Snape (Ed.), Educational transitions: Moving stories from around the world (pp. 107-124). New York: Routledge.

Galton, M. (2010b). Going with the flow or back to normal? The impact of creative practitioners in schools and classrooms. Research Papers in Education, 25, 4, 355-375.

Gandini, L., Hill, L., Caldwell, L., \& Schwall, C. (2005). The context and inspiration of our work, In L. Gandini, L. Hill, L. Caldwell, \& C. Schwall (Eds.), In the spirit of the studio: learning from the atelier of Reggio Emilia (pp. 1-5). New York: Teachers College Press.

Gorton, H. (2012). 'Are they ready?' 'Will they cope?' An exploration of the journey from pre-school to school for children with additional support needs who had their school entry delayed. Unpublished doctoral thesis. Dundee: University of Dundee.

Grainger, T., Goouch, K., \& Lambirth, A. (2005). Creativity and writing. London: Routledge.

Hannah, E., Gorton, H., \& Jindal-Snape, D. (2010). Small steps: Perspectives on understanding and supporting children starting school in Scotland. In D. JindalSnape (Ed.), Educational transitions: Moving stories from around the world (pp. 51-67). New York: Routledge.

Jindal-Snape, D. (2009). Transitions from early years to primary school. Dundee: Report for Primary School Parents' Council, Dundee.

Jindal-Snape, D. (Editor) (2010a). Educational transitions: Moving stories from around the world. New York: Routledge. Retrieved from http://www.routledgeedu cation.com/books/Educational-Transi tions-isbn9780415805919

Jindal-Snape, D. (2010b). Setting the scene: Educational transitions and moving. In 
D. Jindal-Snape (Ed.), Educational transitions: Moving stories from around the world. New York: Routledge.

Jindal-Snape, D. (2010c). Parents' experience of pre-school to primary school transition. Dundee: Report for Primary School 'A', Dundee.

Jindal-Snape, D. (Forthcoming). Primary-Secondary Transition. In S. Capel, M. Leask, \& T. Turner, Learning to teach in the secondary school: A companion to school experience, 6th Edition. New York: Routledge.

Jindal-Snape, D., Baird, L., \& Miller, K. (2011). A longitudinal study to investigate the effectiveness of the Guitar Hero project in supporting transition from P7-S1. Dundee: Report for Learning and Teaching Scotland.

Jindal-Snape, D., \& Foggie, J. (2008). A holistic approach to primary-secondary transitions. Improving Schools, 11, 5-18.

Jindal-Snape, D. \& Foggie, J. (2009). Now I have a Voice! Supporting transitions in the community. Dundee: Report for The Reintegration Project, Perth \& Kinross Children's Services.

Jindal-Snape, D., \& Miller D.J. (2008). A challenge of living? Understanding the psycho-social processes of the child during primary-secondary transition through resilience and self-esteem theories. Educational Psychology Review, 20, 217-236.

Jindal-Snape, D., \& Miller, D.J. (2010). Understanding transitions through self-esteem and resilience. In D. Jindal-Snape (Ed.), Educational transitions: Moving stories from around the world (pp. 11-32). New York: Routledge.

Jindal-Snape, D., Miller, K., \& Baird, L. (2010). Guitar Hero supporting the transition from P7-S1: Planning, preparation and anticipated effectiveness. Dundee: Report for Learning and Teaching Scotland.

Jindal-Snape, D., Snape, N., \& Snape, A. (2011). Shall we play? Pre-school to primary school transition story book (illustrations by Johanne Cameron). Retrieved from http://www.dundee.ac.uk/eswce/ people/djindalsnape/transitions/
Jindal-Snape, D., Vettraino, E., Lowson, A., \& McDuff, W. (2011). Using creative drama to facilitate primary-secondary transition, Education 3-13, 4, 383-394. Retrieved from http://dx.doi. org/10.1080/03004271003727531

Lopez, E.D.S., Eng, E., Robinson, N., \& Wang, C.C. (2005). Photovoice as a communitybased participatory research method: A case study with African American breast cancer survivors in rural eastern North Carolina. In B.A. Israel, E. Eng, A.J. Schulz, \& E.A. Parker (Eds.), Methods in community-based participatory research for health (pp. 326-348).

LTS. (2004). Creativity Counts: A Report of Findings from Schools. Dundee: Learning and Teaching Scotland.

LTS. (n.d.). Curriculum for Excellence. Retrieved from http://www.Itscotland.org.uk/under standingthecurriculum/whatiscurricu lumforexcellence/index.asp

Luthar, S. S. (2006). Resilience in development: A synthesis of research across five decades. In D. Cicchetti \& D. J. Cohen (Eds.), Developmental psychopathology: Risk, disorder, and adaptation (pp. 739795). New York: Wiley.

Matthews, L. (2007). Can the process of transition for incoming secondary pupils be supported through a creative art project? International Journal of Art \& Design Education, 26, 3, 336-344.

Miller, D.J., Hudson, A., Miller, A., \& Shimi, J. (2010). Nintendogs project, Report for LTS. Dundee: University of Dundee.

Mruk, C. (1999). Self-esteem: research, theory and practice. London: Free Association Books.

Newman, T., \& Blackburn, S. (2002). Transitions in the lives of children and young people: Resilience factors. Edinburgh: Scottish Executive Education Department.

Peters, S. (2010). Shifting the lens: Re-framing the view of learners and learning during the transition from early childhood education to school in New Zealand. In D. Jindal-Snape (Ed.), Educational transitions: Moving stories from around the world (pp. 68-84). New York: Routledge. 
Pietarinen, J., Soini, T., \& Pyhältö, K. (2010). Learning and well-being in transitions - how to promote pupils' active learning agency? In D. Jindal-Snape (Ed.), Educational transitions: Moving stories from around the world (pp. 143-158). New York: Routledge.

Schacter, J., Thum, Y., \& Zifkin, D. (2006). How much does creative teaching enhance elementary school students' achievement? Journal of Creative Behavior, 40(1), 47-72.

Whitebread, D., Coltman, P., Jameson, H., \& Lander, R. (2009). Play, cognition and self-regulation: What exactly are children learning when they learn through play? Educational \& Child Psychology, 26(2), 40-52.
Wigfield, A., Eccles, J. S., Mac Iver, D., Redman, D. A., \& Midgley, C. (1991). Transitions during early adolescence: Changes in children's domain-specific self-perceptions and general self-esteem across the transition to junior high school. Developmental Psychology, 27, 552-565.

Wood, R., \& Ashfield, J. (2008). The use of the interactive whiteboard for creative teaching and learning in literacy and mathematics: a case study. British Journal of Educational Technology, 39(1), 84-96.

Wyse, D., \& Spendlove, D. (2007). Partners in creativity: Action research and Creative Partnerships, Education 3-13, 35(2), 181-191.

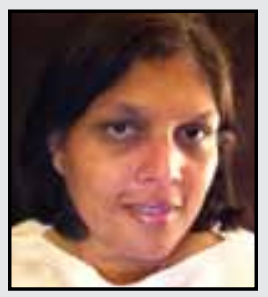

Divya Jindal-Snape is Professor of Education, Inclusion and Life Transitions in the School of Education, Social Work and Community Education at the University of Dundee. She has published extensively in the area of transitions and is also involved in designing creative educational resources to facilitate educational and life transitions. She is the convenor of Transformative Change: Educational and Life Transitions (TCELT) research network.

LINKTO:

http://www.dundee.ac.uk/eswce/people/djindalsnape.htm http://www.dundee.ac.uk/eswce/research/crital/tcelt.htm 